\title{
O uso do jogo educacional "Eu sei Contar" como auxílio da matemática no ensino infantil
}

\author{
Eduardo Jorge Lira A. da Silva', Fernanda Gabriela da Sousa Pires ${ }^{1}$ \\ ${ }^{1}$ Escola Superior de Tecnologia - Universidade do Estado do Amazonas (UEA) \\ Av. Darcy Vargas, 1200, Parque Dez - Manaus - AM - Brazil \\ eduardu.silva@hotmail.com, pires.gabriela@hotmail.com
}

\begin{abstract}
The use of technological tools in early stages of education still finds great resistance by schools and educators. A diagnosis was made with garden students II in order to identify the need and the impact that an educational game causes on the performance of students in the context of the math teaching. The game application "Eu sei contar" allowed to verify this impact and to compare it with previous researches. The results show a 30\% improvement in learning and association of natural numbers, which made it possible to conclude that the use of educational software in schools contributes positively to student achievement.
\end{abstract}

Resumo. $O$ uso de ferramentas tecnológicas em séries primárias ainda encontra grande resistência por parte das escolas e educadores. Foi realizado um diagnóstico com alunos de jardim II a fim de identificar esta necessidade e o impacto que um jogo educacional causa no desempenho dos alunos no contexto do ensino da disciplina de matemática. A aplicação do Jogo "Eu sei Contar" permitiu verificar este impacto e compará-lo com pesquisas anteriores. Os resultados apontam uma melhora de 30\% no aprendizado e associação dos números naturais, o que possibilitou concluir que o uso de softwares educacionais nas escolas contribui positivamente no rendimento dos alunos.

\section{Introdução}

Observando o contexto da educação no Brasil e o recorrente avanço da tecnologia digital, é possível observar que a aplicação de recursos tecnológicos digitais ainda encontra dificuldades para ser implantado ao ambiente escolar, segundo Kenski (2003) o uso inadequado dessas tecnologias compromete o ensino e cria um sentimento aversivo em relação à sua utilização em outras atividades educacionais, difícil de ser superado. Saber utilizar adequadamente essas tecnologias para fins educacionais é uma nova exigência da sociedade atual em relação ao desempenho dos educadores seja por diretrizes das próprias escolas ou decorrente de uma resistência por parte dos educadores.

Moran (2004) afirma que a internet é uma fantástica evolução tecnológica, e com ela podemos aprender de muitas formas, em lugares diferentes, de formas diferentes. A sociedade como um todo é um espaço privilegiado de aprendizagem, mas ainda é a escola a organizadora e certificadora principal do processo de ensino aprendizagem. A 
internet é uma porta para o aprendizado expandido, e nela podemos encontrar diversos recursos aplicáveis em sala de aula para suprir uma necessidade específica dos alunos ou do próprio educador.

Segundo Bee e Boyd (2009) cada criança cria um conjunto de ideias ou suposições centrais sobre o mundo, sobre si mesma e sobre relacionamentos com outras pessoas, conhecido como conjunto de modelos internos de experiência. Experiências estas que, segundo os autores, são melhores exploradas e descobertas dentro de uma sala de aula por meio de exercícios lúdicos e da própria interação entre aluno-professor e aluno-aluno.

Como trabalhos relacionados, podemos citar Silva e Passerino (2007), que descrevem o uso de um software desenvolvido em Flash para o ensino da educação ambiental, por meio de simulação e administração de uma fazenda, e Grando e Tarouco (2008), que propõem a utilização de jogos RPG como ferramenta educacional em sala de aula.

O presente artigo mostra a aplicação do Jogo "Eu sei contar" (plataforma web) em uma turma de Ensino Infantil -Jardim II, tendo como unidade amostral crianças de 5 e 6 anos de idade, o objetivo é analisar o impacto causado pela utilização de ferramentas digitais gamificadas para aprendizagem infantil, considerando o referencial bibliográfico existente (Kenski e Mattei) e os estudos sobre aprendizagem lúdica (Affonso) e as fases de desenvolvimento humano (Vygotsky).

\section{Contextualização}

Segundo Mattei (2011), o uso da informática pelas escolas cresce a cada dia, tanto na área administrativa quanto na área pedagógica. Seu uso adequado, oportuniza o desenvolvimento e a organização na construção do pensamento, bem como, desperta o interesse e a curiosidade dos alunos, elementos fundamentais para a construção do conhecimento. Portanto, é fundamental inseri-la e usá-la nas salas de aula desde as classes primárias, para que o aluno, que inicia a sua vida escolar, mantenha este contato com tal tecnologia que o rodeia no ambiente externo à sala de aula e que já é presente na sua vida pessoal.

Sendo assim, a principal questão de pesquisa do presente projeto tem por objetivo determinar e comparar a eficácia do uso do software educacional "Eu sei Contar" na aprendizagem da matemática por alunos do ensino infantil, afim de responder a seguinte questão: $\mathrm{O}$ uso de jogos educacionais nas séries primárias estimula o aprendizado dos alunos e desperta o interesse para a associação dos conteúdos? O que nos leva a seguinte hipótese:

H1-1: O uso do jogo educacional: "Eu sei Contar" no ensino da Matemática, em uma turma de jardim dois, pode auxiliar o aluno no aprendizado e associação dos números naturais.

Para verificar a veracidade desta hipótese, foram analisados os resultados individuais de cada aluno gerados pelo software/jogo ao final da atividade e os dados inseridos em uma tabela sobre a taxa de aproveitamento dos alunos antes e depois da aplicação do software em sala. 
De acordo com os Parâmetros Curriculares Nacionais - PCN do ensino fundamental (Brasil, 1997 e 1998), referentes ao ensino da matemática no primeiro ciclo, a criança nessa faixa etária de 5 e 6 anos precisa compreender e associar os números naturais a partir de seus diferentes usos no contexto social. A utilização do software/jogo "Eu sei contar" permite que o aluno identifique o uso dos números naturais em situações comuns ao seu cotidiano, como a contagem de objetos, frutas, etc. Além de proporcionar a imersão do aluno por meio de animações e sons.

Para a realização da pesquisa, foi realizada uma observação diagnóstica com alunos e professor do jardim dois a fim de identificar a maneira como o conteúdo programático era passado e quais recursos eram utilizados pelo professor para executar tal ação. Como unidades experimentais, temos 15 alunos do ensino infantil da Escola São Jorge no ano letivo de 2016.

\section{Design do Experimento}

Por se tratar de uma pesquisa do tipo Experimental, sua estrutura da pesquisa foi constituída por quatro fases, estas que, ao término, forneceram dados utilizados para a verificação da melhoria na retenção do conteúdo por parte dos alunos durante as aulas de matemática. A execução da pesquisa envolveu as seguintes fases:

- Realização de diagnóstico com os alunos para identificar os interesses e o nível de familiaridade com tecnologia;

- Aplicação de ludodiagnóstico para identificar a familiaridade dos alunos com o conteúdo de matemática;

- Apresentação do jogo educacional "Eu sei Contar" e coleta dos dados das atividades realizadas;

- Análise estatística dos dados.

A fase número um foi voltada para o diagnóstico dos alunos, da professora responsável e do ambiente em geral. Esta foi executada primeiramente por meio de um questionário estruturado com a professora da turma, com perguntas objetivas que permitem identificar a abordagem pedagógica utilizada em classe e sua metodologia de avaliação. Tais observações permitiram levantar algumas conclusões acerca da metodologia de ensino utilizada em turmas do jardim dois.

Após as observações iniciais, foi iniciada a fase dois do projeto, que manteve como foco principal o aluno. O objetivo dessa fase foi identificar o nível de conhecimento do conteúdo obtido pela criança ao longo do ano letivo. Para alcançar esses dados, um ludodiagnóstico foi aplicado que, segundo Affonso (2012), é um instrumento de investigação clínica no qual, por meio da utilização de brinquedos, estruturados ou não, o profissional procura estabelecer um vínculo terapêutico com a criança, visando o diagnóstico de sua personalidade. O mesmo foi realizado por meio de dois exercícios matemáticos de ordenação numérica e soma de inteiros, onde o aluno deveria organizar os blocos numerados em sequência crescente seguindo orientações do observador, e posteriormente resolver três questões de soma, como exemplo: $1+2=3$, $3+3=6$. Para a projeção da tabela, foi realizada o cálculo de acordo com os acertos dos alunos em relação à questão específica. 
VI Congresso Brasileiro de Informática na Educação (CBIE 2017)

Anais do XXIII Workshop de Informática na Escola (WIE 2017)

Tabela 1. Desempenho nas atividades Lúdicas

\begin{tabular}{|l|c|}
\hline \multicolumn{1}{|c|}{ Atividades } & Desempenho Geral \\
\hline Ordenação de 0 a 10 & $76.9 \%$ \\
\hline Ordenação de 11 a 20 & $61.5 \%$ \\
\hline Ordenação de 21 a 30 & $53.8 \%$ \\
\hline Questão de Soma 1 & $100 \%$ \\
\hline Questão de Soma 2 & $61.5 \%$ \\
\hline Questão de Soma 3 & $53.8 \%$ \\
\hline
\end{tabular}

A terceira fase refere-se à aplicação do software "Eu sei Contar" em sala de aula. Após a organização da sala em semicírculo, cada aluno foi convidado a realizar duas atividades do software, que traz como conteúdo base a formação e ordenação dos números naturais positivos, enquanto os alunos observadores contribuíam para que o colega que estaria utilizando o software conseguisse realizar a atividade.

Em relação a organização e disposição das cadeiras em semicírculo, Figueiras (2010) afirma que existem fortes relações entre as pessoas e o seu meio, pois todo o meio ou contexto em que se produz a conduta possui os seus limites físicos, recursos disponíveis, que facilitam, limitam e ordenam a intenção dos sujeitos. A necessidade de comunicação entre os alunos durante a execução da atividade favorece essa relação e consequentemente a construção do conhecimento, sendo obtida por meio da proximidade dos alunos e da visão facilitada da atividade proporcionada pela disposição das cadeiras e do professor.

Ao término da aplicação do software e final da aula, a quarta fase foi iniciada com uma nova entrevista realizada com a professora a fim de reconhecer os benefícios e dificuldades encontradas por ela durante a aplicação do software. Para este momento, foi utilizado um questionário semiestruturado. Com a coleta dos dados obtidos no jogo, foi possível identificar se a aplicação de um software educacional nas séries primárias, especificamente no jardim dois, traz algum benefício ou torna mais simples e eficaz o ensino da matemática.

\section{Ameaças à Validade}

Em relação às ameaças à validade do experimento, não foram identificadas ameaças à validade interna, porém, devido às unidades experimentais da pesquisa partirem de uma única fonte, podem ter características próprias que não são válidas para todas as demais escolas do país. Logo, há uma ameaça à validade externa na interação de seleção, o que dificulta a generalização dos resultados.

O uso de softwares/jogos em sala de aula pode gerar mudanças no nível de contato da criança com recursos tecnológicos, pois passam a ser fatores que podem influenciar nos resultados finais, como exemplo, os níveis de conhecimento da criança sobre informática e sua familiarização com recursos tecnológicos. 
VI Congresso Brasileiro de Informática na Educação (CBIE 2017)

Anais do XXIII Workshop de Informática na Escola (WIE 2017)

\section{Análise de Software}

O jogo educacional "Eu sei Contar" é um software de plataforma web encontrado no repositório online "Escola Games". Neste repositório encontramos jogos educacionais voltados para todas as disciplinas do ensino infantil, e para todos os públicos.

\subsection{Interface do software}

Em relação ao software/jogo "Eu sei Contar", a interface é simples e intuitiva, além de ser extremamente carregada de elementos visuais tais como, imagens, animações e personagens cartoon. Segundo Vygotsky (1998), para entendermos o desenvolvimento da criança, é necessário levar em conta as necessidades dela e os incentivos que são eficazes para colocá-las em ação. O seu avanço está ligado a uma mudança nas motivações e incentivos, por exemplo: aquilo que é de interesse para um bebê não o é para uma criança um pouco maior. Devido a este fator, o jogo "Eu sei Contar" foi selecionado para integrar a etapa número três, além de o conteúdo apresentado no jogo seguir o plano de ensino da professora responsável.

\subsection{Atividades}

As atividades contidas no jogo são duas. A primeira atividade (figura 1) refere-se a contagem de elementos, onde o jogador deve visualizar um conjunto de objetos e em seguida deve selecionar o número correspondente aos elementos contidos no conjunto. Ao total são 5 questões geradas aleatoriamente sempre que o jogo é recarregado. Ao final de cada atividade uma pontuação é gerada e acumulada.

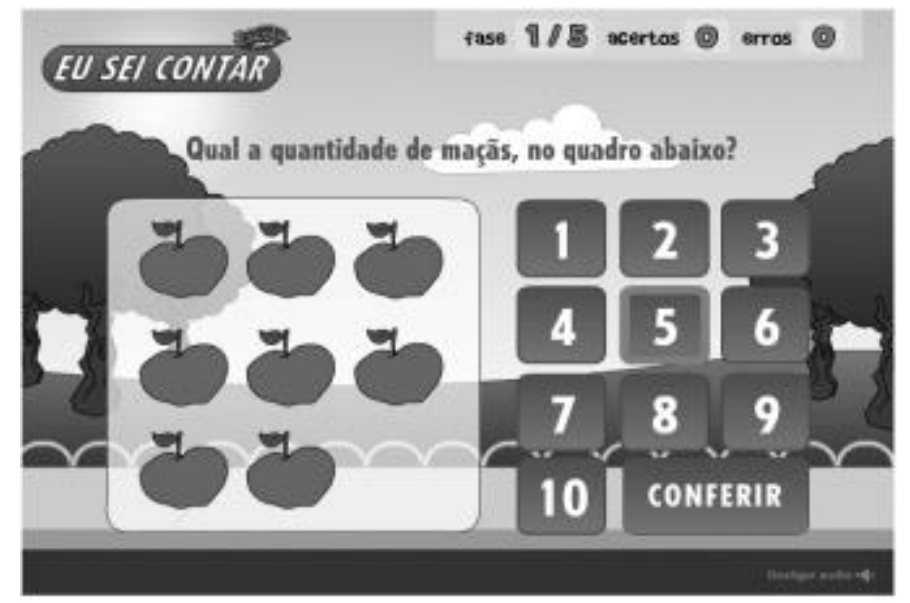

Figura 1. Atividade 1 do jogo Eu Sei Contar

A segunda atividade (figura 2) estimula o jogador a treinar a contagem sequencial dos números naturais por meio de um infinity, onde o jogador precisa coletar 10 estrelas, que surgem em alturas diferentes, para alcançar o final da fase.

Durante todas as atividades a pronuncia dos números é feita por meio de sons, tornando-se feedbacks auditivos para o jogador. Além disso, os números em sua forma cardinal são mostrados com bastante frequência, facilitando a associação da criança com os elementos do jogo. 
VI Congresso Brasileiro de Informática na Educação (CBIE 2017)

Anais do XXIII Workshop de Informática na Escola (WIE 2017)

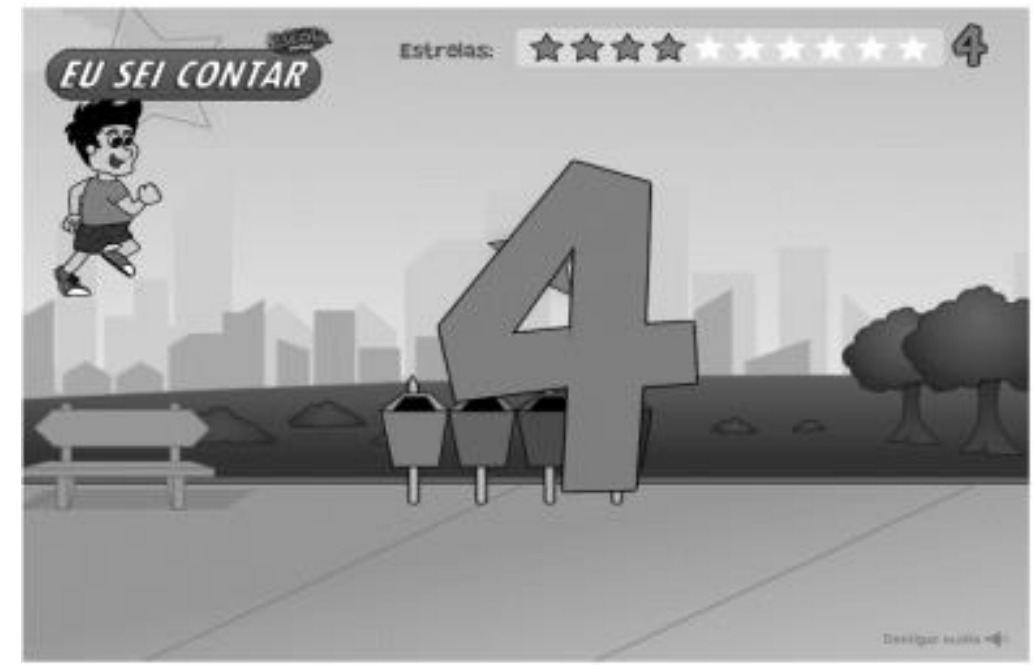

Figura 2. Atividade 2 do jogo Eu Sei Contar

\section{Resultados}

\subsection{Apresentação dos Dados}

Para manter a confidencialidade e privacidade dos alunos avaliados, foram retiradas quaisquer informações que pudessem identificar o sujeito avaliado. A tabela 2 apresenta o rendimento dos alunos. Sendo composta por 13 alunos participantes. Afim de certificar o impacto no rendimento dos alunos, após aplicação do software, foram aplicadas as mesmas atividades lúdicas apresentadas na fase um, contendo algumas alterações na atividade 2 .

Tabela 2. Desempenho nas atividades Lúdicas

\begin{tabular}{|l|c|c|}
\hline \multicolumn{1}{|c|}{ Alunos } & $\begin{array}{c}\text { Exercícios sem Aplicação do } \\
\text { Software }\end{array}$ & $\begin{array}{c}\text { Exercícios com a aplicação do } \\
\text { software }\end{array}$ \\
\hline Aluno 1 & $50 \%$ & $66 \%$ \\
\hline Aluno 2 & $83 \%$ & $100 \%$ \\
\hline Aluno 3 & $83 \%$ & $83 \%$ \\
\hline Aluno 4 & $83 \%$ & $100 \%$ \\
\hline Aluno 5 & $83 \%$ & $83 \%$ \\
\hline Aluno 6 & $50 \%$ & $83 \%$ \\
\hline Aluno 7 & $100 \%$ & $100 \%$ \\
\hline Aluno 8 & $50 \%$ & $83 \%$ \\
\hline Aluno 9 & $16 \%$ & $66 \%$ \\
\hline Aluno 10 & $100 \%$ & $100 \%$ \\
\hline Aluno 11 & $66 \%$ & $83 \%$ \\
\hline Aluno 12 & $16 \%$ & $66 \%$ \\
\hline Aluno 13 & $100 \%$ & $100 \%$ \\
\hline
\end{tabular}


VI Congresso Brasileiro de Informática na Educação (CBIE 2017)

Anais do XXIII Workshop de Informática na Escola (WIE 2017)

\subsection{Discussão dos resultados}

O presente artigo teve como objetivo investigar o impacto do uso de softwares educacionais para o ensino da disciplina de matemática para alunos do ensino infantil (Jardim II). Tal problemática levou a seguinte hipótese:

H1-1: O uso do jogo educacional: "Eu sei Contar" no ensino da Matemática, em uma turma de jardim dois, pode auxiliar o aluno no aprendizado e associação dos números naturais.

Partindo das análises dos dados gerados por meio do software "Eu sei Contar" e da reaplicação do ludodiagnóstico, notou-se uma melhora significativa de 30\% no rendimento dos alunos após a aplicação do software em sala de aula. As mudanças são mais perceptíveis quando se observa o rendimento, antes da aplicação do software e após a aplicação, de alunos que possuíam a média de aproveitamento muito baixa e que tiveram uma melhora no desempenho após o uso do jogo, e testada no novo ludodiagnóstico, uma vez que as atividades sofreram pequenas alterações, para não influenciar no resultado final.

\section{Conclusão}

O presente trabalho apresentou um breve experimento a respeito da implantação de tecnologias digitais, tais como jogos educacionais, em uma turma de ensino infantil no ensino da matemática. Após diagnósticos e testes utilizando o software educacional "Eu sei Contar" pode-se comprovar o impacto positivo que o uso de recursos digitais pode causar no desempenho de alunos em relação ao conteúdo ministrado em sala de aula, uma vez que se observou uma melhora significativa no rendimento dos alunos após aplicação de ludodiagnóstico. Espera-se que trabalhos futuros possam contribuir para o crescimento e enriquecimento da comunidade com intuito de ampliar as possibilidades destes benefícios.

\section{Referências}

MATTEI, C. (2011). O prazer de aprender com a informática na Educação Infantil. Instituto Catarinense de Pós-Graduação, Associação Educacional Leonardo da Vinci.

AFFONSO, R. M. L. (2012). Ludodiagnóstico: Investigação clínica através do brinquedo. São Paulo, SP: Artmed Editora Ltda.

BEE, H., \& BOYD, D. (2009). A criança em desenvolvimento. Artmed Editora.

BRASIL. Ministério da Educação. Secretaria de Educação Fundamental. Parâmetros Curriculares Nacionais: Matemática (1o e 20 ciclos do ensino fundamental). v. 3. Brasília: MEC, 1997.

MORAN, J. M. (2004). Os novos espaços de atuação do educador com as tecnologias. Conhecimento local e conhecimento universal: diversidade, mídias e tecnologias na educação. Curitiba: Champagnat, 245-253.

KENSKI, V. M. (2003). Aprendizagem mediada pela tecnologia. Revista diálogo educacional, Curitiba, 4(10), 47-56. 
VI Congresso Brasileiro de Informática na Educação (CBIE 2017)

Anais do XXIII Workshop de Informática na Escola (WIE 2017)

VYGOTSKY, L. S. (1988). Aprendizagem e desenvolvimento intelectual na idade escolar. _set al. Linguagem, desenvolvimento e aprendizagem. São Paulo: Ícone: EDUSP.

VIEIRA, L. D. S., \& Oliveira, V. X. (2010). A importância dos jogos e brincadeiras para o processo de alfabetização e letramento. Encontro de Produção Científica e Tecnológica- EPTC, 5, 1-11.

MERCADO, L. P. L. (1998). Formação docente e novas tecnologias. Anais do IV Congresso da Rede Ibero-americana de Informática Educativa (pp. 1-8).

PRIETO, L. M., Trevisan, M. D. C. B., Danezi, M. I., \& Falkembach, G. M. (2005). Uso das tecnologias digitais em atividades didáticas nas séries iniciais. RENOTE, 3(1).

GRANDO, A., \& TAROUCO, L. M. R. (2008). O uso de jogos educacionais do tipo RPG na educação. RENOTE, 6(1).

SILVA, A. A., \& PASSERINO, L. M. (2007). A Fazenda Software Educativo para a Educação Ambiental. RENOTE, 5(2).

FILGUEIRAS, M. S. C. (2010). O espaço e o seu impacto educativo: quais as principais características da gestão e organização do espaço sala em educação infantil (Doctoral dissertation).

EU SEI CONTAR. Disponível em $<$ http://www.escolagames.com.br $>$. Acesso em 10 out 2016. 